\title{
Arrhythmogenic right ventricular cardiomyopathy
}

\author{
Roopali Soni, ${ }^{1}$ Yvette Oade ${ }^{2}$ \\ ${ }^{1}$ Department of Paediatrics, Yorkshire Deanery, Leeds, UK; \\ 2Department of Paediatrics, Calderdale Royal Hospital, Halifax, UK
}

Correspondence to Dr Roopali,Soni, roopali.soni@gmail.com

\section{Summary}

Arrhythmogenic right ventricular cardiomyopathy (ARVC) is a rare inherited disease of the heart muscle that causes ventricular tachyarrhythmias and sudden death in young people and athletes. It results in fibrofatty replacement of the right ventricle, and the subepicardial region of the left ventricle. It is the most common cause of sudden cardiac death in young people after hypertrophic heart disease. Diagnosis can be difficult and at present there is no cure for ARVC. Prevention of sudden death is the most important management strategy. Paediatricians need to be aware of the possibility of ARVC in adolescents and young adults presenting with palpitations, fatigue, syncope or cardiac arrest. The authors present two cases of apparently healthy teenage boys who died suddenly and unexpectedly. Postmortem examination of the myocardium was strongly suggestive of ARVC in both cases.

\section{BACKGROUND}

ARVC is the most common cause of sudden cardiac death in young people after hypertrophic heart disease. The sudden and unexpected death of these two apparently healthy young boys was a devastating experience for the families.

Paediatricians need to be aware of the possibility of ARVC in adolescents and young adults presenting with palpitations, fatigue, syncope or cardiac arrest usually during exercise. The occurrence of sudden death is not related to disease progression and sudden death can be the first manifestation of the disease.

\section{CASE PRESENTATION}

\section{Case 1}

A 13-year-old boy collapsed suddenly while playing in a local park. He was involved in a verbal altercation and a scuffle with friends, lost his balance and hit his head on a railing before losing consciousness. Witnesses reported that he went pale and developed shallow breathing. Cardiopulmonary resuscitation (CPR) was initiated by a passerby and then by paramedics. Full resuscitation attempts in A\&E were unsuccessful.

He had been under Paediatric follow-up for a medical history of two collapses and a number of dizzy spells over the preceding 5 years. Baseline investigations including an ECG and EEG were reported to be normal. He had failed to attend for a 24-h ECG and outpatient appointments over the previous year.

The postmortem findings showed a large heart with focal myocarditis and some small areas of fibrosis. A cardiologist reviewed the previous ECG and commented on the possibility of abnormal T waves. The patients' father had died suddenly at 18 years of age and the diagnosis at postmortem had been 'cardiac arrhythmia secondary to resolving myocarditis and myocardial scarring'. The tissues were not available for review.

\section{Case 2}

A 17-year-old boy who was previously fit and healthy was found unconscious in bed by his mother. He was pale, unresponsive and had shallow breathing. CPR by paramedics failed to revive him. There was no significant medical history to account for the sudden death.

Postmortem examination demonstrated a large heart. The right ventricle showed patchy replacement of myocytes by fatty tissue with accompanying myocyte atrophy which was strongly suggestive of ARVC. The boys paternal uncle had died suddenly at 46 years of age under similar circumstances.

\section{INVESTIGATIONS}

The postmortem findings in both cases were strongly suggestive of ARVC.

\section{DISCUSSION}

The first historical description of the condition was in the book De Motu Cordis et Aneurysmatibus, published in 1736 by Giovanni Maria Lancisi, the Pope's physician and Professor of Anatomy in Rome. He reported a family with disease recurrence in four generations. Symptoms included palpitations, heart failure, dilatation and aneurysms of the right ventricle and sudden death.

In the late 1970s a team of Cardiologists in France noted changes in the myocardium of the right ventricle in their patients who suffered from ventricular tachycardia (VT). They called it arrhythmogenic right ventricular dysplasia. In the 1980s and 90s the same changes in the heart muscle of young people who had died suddenly were noted, especially in athletes with a tendency for the condition to run in families. The condition was thought to occur due to progressive change in the myocardium as a consequence of cell death occurring after birth, usually during childhood, the name was changed to 'arrhythmogenic right ventricular cardiomyopathy'. 
At first, ARVC was described as a disease of the right ventricle, but with time, the changes in the heart muscle can also affect the left ventricle. It does not affect the atrial myocardium. The identification of left dominant phenotypes has supported the adoption of the broader term arrhythmogenic cardiomyopathy.

\section{Genetics}

ARVC is a familial disease in at least $50 \%$ of cases and is typically transmitted as an autosomal dominant trait with variable penetrance and incomplete expression. There is an autosomal recessive variant called Naxos disease. ARVC has been found to be mainly a disease of the cardiomyocyte junction and plakophilin-2 is the most frequent targeted gene. ${ }^{1}$

The estimated prevalence of the disease in the general population ranges from 1 in 2500 to 1 in 5000. Differences in geographical distribution have been identified with an increased prevalence in certain regions in Italy and Greece. $^{2}$

\section{Pathogenesis}

In patients with ARVC the cardiomyocyte desmosomal proteins are defective and cannot keep the myocytes together when under stress, for example, during exercise. The myocytes become detached and die. The damaged and dead cells become fibrous and cause scarring. Fatty deposits build up, in an attempt to repair the damage. The thin-walled areas of the right ventricle and the posterolateral wall of the left ventricle are structurally more vulnerable to mechanical stress.

The fibrofatty replacement interferes with electrical impulse conduction, and is the key cause of epsilon waves, right bundle branch block, late potentials, and re-entrant ventricular arrhythmias.

\section{Clinical presentation}

Clinical manifestations of ARVC usually occur during adolescence and young adulthood. The disease presentation is highly variable even within families. Paediatricians should be aware of the possibility of ARVC in adolescents and young adults presenting with palpitations, fatigue, syncope or cardiac arrest usually during exercise.

ECG changes such as T-wave inversion in V1-V3 (except in those younger than 12 years) or premature ventricular complexes of left bundle branch block morphology should also arouse suspicion of ARVC, even in asymptomatic individuals. Ventricular arrhythmias range from premature ventricular complexes to sustained VT or ventricular fibrillation (VF) leading to cardiac arrest. VF is the mechanism of instantaneous sudden death in young people and athletes with ARVC, who are often previously asymptomatic.

The incidence of sudden death varies from $0.1 \%$ to $3.0 \%$ per year in adults with ARVC. However, this rate might be higher in young people, when sudden death can be the first sign of the disease. ${ }^{1}$ The mean age at diagnosis is 31 years ( \pm 13 ; range: $4-64$ years). ${ }^{3}$

\section{Investigations and diagnosis}

The diagnosis of ARVC usually rests on fulfilling a set of clinical criteria, as defined by an international ARVC task force.
There are several ECG features in the diagnostic criteria of ARVC

- T-wave inversion in the right precordial leads (V1-V3) is the most common repolarisation abnormality (except in children under 12 years)

- Prolongation of right precordial ORS duration (110 or more)

- Epsilon waves: small amplitude potentials occurring after the QRS complex and before the onset of the $\mathrm{T}$ waves

- An S wave duration of more than $55 \mathrm{~ms}$ in V1-V3

The routine assessment of patients with suspected ARVC includes clinical and family history, physical examination, chest radiograph, 12-lead ECG, 24-h ambulatory ECG, signal-averaged ECG, stress test and two-dimensional echocardiography. Some patients might require further examination by contrast-enhanced cardiac MRI, contrast angiography, and endomyocardial biopsy. ${ }^{1}$

\section{Management}

Effective treatment is available for patients with ARVC. Restriction of physical exercise, antiarrhythmic drug and $\beta$-blocker therapy, and implantable cardioverter-defibrillator (ICD) are life-saving. The clinical challenge is to improve risk stratification for better identification of those patients who most benefit from one or a combination of the therapies. Evidence suggests that asymptomatic patients or healthy gene carriers do not require prophylactic treatment. They should instead undergo regular cardiac follow-up.

Patients considered at high risk of sudden cardiac death should receive an implantable ICD. Heart transplantation is the final therapeutic option in case of refractory congestive heart failure or untreatable ventricular arrhythmias.

\section{Learning points}

ARVC is a rare inherited disease of the heart muscle that causes ventricular tachyarrhythmias and sudden death in young people.

- Paediatricians need to be aware of the possibility of ARVC in adolescents and young adults presenting with palpitations, fatigue, syncope or cardiac arrest usually during exercise.

- The diagnosis usually rests on fulfilling a set of clinical criteria, as defined by an international ARVC task force.

- Diagnosis can be difficult and at present there is no cure for ARVC.

- Prevention of sudden death is the most important management strategy.

Competing interests None.

Patient consent Obtained.

\section{REFERENCES}

1. Basso C, Corrado D, Marcus Fl, et al. Arrhythmogenic right ventricular cardiomyopathy. Lancet 2009;373:1289-300.

2. Pérez Díez D, Brugada J. Diagnosis and management of right ventricula dysplasia. EJournal of the ESC Council for Cardiology Practice 2008;17.

3. McNally E, MacLeod H, Dellefave L. Arrhythmogenic right ventricular dysplasia/cardiomyopathy. GeneReviews 2005, revised 2009.

4. Mckenna WJ, Elliott P, et al. Inherited heart conditions, Arrhythmogenic right ventricular cardiomyopathy. British Heart Foundation 2009;13-22. 


\section{BMJ Case Reports}

This pdf has been created automatically from the final edited text and images.

Copyright 2011 BMJ Publishing Group. All rights reserved. For permission to reuse any of this content visit http://group.bmj.com/group/rights-licensing/permissions.

BMJ Case Report Fellows may re-use this article for personal use and teaching without any further permission.

Please cite this article as follows (you will need to access the article online to obtain the date of publication).

Soni R, Oade Y. Arrhythmogenic right ventricular cardiomyopathy. BMJ Case Reports 2011;10.1136/bcr.05.2011.4242, date of publication

Become a Fellow of BMJ Case Reports today and you can:

- Submit as many cases as you like

- Enjoy fast sympathetic peer review and rapid publication of accepted articles

- Access all the published articles

- Re-use any of the published material for personal use and teaching without further permission

For information on Institutional Fellowships contact consortiasales@bmjgroup.com

Visit casereports.bmj.com for more articles like this and to become a Fellow 